\title{
AWARENESS DURING GENERAL ANAESTHESIA
}

\author{
DAVID L. SCOTT, M.R.C.S., L.R.C.P., F.F.A.R.C.S.I. ${ }^{\circ}$
}

THE PROBLEM OF awareness during anaesthesia has existed since the introduction of the muscle relaxant technique. Any study of the problem must necessarily involve a study of the unconscious mind where such memories are recorded. It must also involve an understanding of some basic psychological mechanisms.

The writer has attempted to correlate the published evidence, both clinical reports and research results, and evaluate this from his own experience in anaesthetics and clinical hypnotherapy. It is emphasized that this is a personal evaluation of a difficult subject, in which "scientific proof", in its normally accepted sense, is virtually impossible.

\section{Historical}

The first account of "awareness" was a letter by Winterbottom, ${ }^{1}$ published in 1950. A brisk correspondence followed, but there was a gap of nearly nine years before further reports appeared, as though anaesthetists were reluctant, or embarrassed, to make such events public.

Then, in 1959, Graff and Phillips ${ }^{2}$ published a case and an editorial ${ }^{3}$ appeared in which it was mentioned that "doubtless there have been others." Two more editorials appeared in the Lancet ${ }^{4}$ and in Anesthesiology ${ }^{5}$ and reports of single or several cases were described by the following authors: Alment, ${ }^{6}{ }^{B} \mathrm{Bahl}$ and Wadwa, ${ }^{7}$ Cheek, ${ }^{8,0}$ Crawford, Harley, Bland and Shah, ${ }^{10}$ Marx, Steen, Schapira, Foster, Arkins, Joffe and Kepes, ${ }^{11}$ Rosen ${ }^{12}{ }^{12}$ Sia, $^{13}$ Smith and McNeil, ${ }^{14}$ Stephen ${ }^{15}$ and Wilson and Turner. ${ }^{16}$

\section{Insufficient anaesthesia or awareness during anaesthesia?}

Winterbottom ${ }^{1}$ correctly described his case as one of insufticient anaesthesia. This patient was ventilated on pure oxygen for nearly an hour, a mistake which can be attributed to lack of knowledge in the early days of the muscle relaxants. Today the concept "awareness during anaesthesia" is generally used, but there should be a distinction between "insufficient anaesthesia" and "awareness during apparent surgical anaesthesia" - as in Bahl and Wadwa's" case.

Sia $^{13}$ grades consciousness during general anaesthesia as: (a) fully conscious, (b) partly conscious, and (c) borderline between consciousness and unconscious. This concept of degrees of consciousness (= potential awareness) merging into unconsciousness (= absence of awareness) is important when understanding this problem.

\section{Studies on awareness}

These have been prospective and retrospective, and have produced conflicting results. The prospective studies have generally failed to confirm ("prove") the

- Consultant Araesthetist, Whiston Hospital. Prescot, Lancs, L35 5or. 
existence of awareness, whereas the retrospective studies, which have been taken from clinical practice, have always revealed evidence of this.

(1) Prospective studies

Levinson ${ }^{17}$ investigated ten adult volunteer patients. At deep planes of EEG-monitored ether anaesthesia, they were exposed to a purposefully alarming comment by the anaesthetist suggestive of an oxygen failure. At interview one month later, none could recall any detail of the operation at the conscious level. When hypnotized, and regressed to the actual operation, eight of the ten displayed marked anxiety, four of these recalling almost exactly the words spoken by the anaesthetist.

Other investigators used pre-recorded tapes which were played back to patients during different types of general anaesthesia. McIntyre, ${ }^{18}$ presented a complex and irrelevant story. Terrell, Sweet, Gladfelter and Stephen ${ }^{18}$ presented a repeated recording which consisted of "numbers, innocuous words, jokes, riddles and stories." These authors stressed that any words or statements did not refer to the patient's specific history or physical condition. Brice, Hetherington and Utting ${ }^{20}$ pre-recorded choir and piano music on tape. Thus these three investigations included a wide variety of material for replay to anaesthetised patients.

Subsequent questioning at the conscious level was carried out by "neutral" observers at different periods up to 7-8 days postoperatively. Terrell et al. ${ }^{16}$ also used hynosis to question the unconscious minds of their subjects using ideomotor finger responses, which method will be described later. None of these three groups of investigators revealed any evidence of awareness or recall.

The following comments are made:

(a) Clinical practice consistently reveals evidence of awareness during anaesthesia. With the exception of Levinson's $\mathrm{s}^{17}$ work, carefully conducted experiment has failed to confirm this.

(b) It may reasonably be considered, therefore, that there is some basic difference between the experimental situation and clinical practice.

(c) Levinson was the only worker to present his patients with a (feigned) threat to life realistically connected to the operative procedure. It must be noted that he secured no positive result by questioning at the conscious level, only by the use of hypnosis.

It is a pity that more detail of the hypnotic technique was not given, as the ethics of this experiment are open to dispute and it seems unlikely that an equivalent experiment will be repeated; indeed, the writer feels strongly that repetition is unjustified, however interesting such results could be.

(d) All the other prospective investigations presented matter which was totally irrelevant to the patient. There could have been little point in the patient paying attention to it even at the conscious level.

(e) This is in marked contrast to the recorded cases of awareness. The information "heard" has always been directly or indirectly concerned with the individual's safety and welfare; in many instances it was what the surgeon said that had been recalled.

(f) It is also interesting that in the series of Brice et al..$^{20}$ there was a higher incidence of dreams involving conversation in the 19 controls to whom no tape was played, i.e. they were only thus exposed to background theatre conversation. These 
TABLE I

Cases Anaesthetised ey Nitrous Oxibe-Oxygen-RelaXant (ippv) Thchique

\begin{tabular}{|c|c|c|c|c|c|c|c|}
\hline & $\begin{array}{l}\text { Case } \\
\text { No. }\end{array}$ & $\begin{array}{l}\text { Pre-op } \\
\text { Anxiety }\end{array}$ & Vision & Hearing & Discomfort & Pain & Upset \\
\hline $\begin{array}{l}\text { Wilson and } \\
\text { Turner. } \\
\text { (150 cases) }\end{array}$ & $\begin{array}{l}1 \\
2 \\
3\end{array}$ & $\begin{array}{l}\text { Yes } \\
\text { Yes }\end{array}$ & No & $\begin{array}{l}\text { Yes } \\
\text { Yes } \\
\text { Yes }\end{array}$ & $\begin{array}{l}\text { No } \\
\text { Yes } \\
\text { No }\end{array}$ & $\begin{array}{l}\text { No } \\
\text { No } \\
\text { Yes }+\end{array}$ & $\begin{array}{l}\text { No } \\
\text { Yes }+ \\
\text { Yes + }\end{array}$ \\
\hline $\begin{array}{l}\text { Hutchinson. } \\
\text { (216 cases) }\end{array}$ & $\begin{array}{l}1 \\
2 \\
\mathbf{3} \\
\mathbf{4} \\
\mathbf{5} \\
\mathbf{6}\end{array}$ & Yes & $\begin{array}{l}\text { No } \\
\text { No } \\
\text { No } \\
\text { No } \\
\text { No } \\
\text { No }\end{array}$ & $\begin{array}{l}\text { None } \\
\text { Yes } \\
\text { Yes + } \\
\text { Yes } \\
\text { Yes } \\
\text { Yes }\end{array}$ & $\begin{array}{l}\text { Yes } \\
\text { No } \\
\text { No } \\
\text { Yes } \\
\text { No } \\
\text { No }\end{array}$ & $\begin{array}{l}\text { No } \\
\text { Yes } \\
\text { Yes } \\
\text { No } \\
\text { Yes } \\
\text { No }\end{array}$ & $\begin{array}{l}\text { No } \\
\text { Yes }++ \\
\text { Yes }++ \\
\text { No } \\
\text { Yes } \\
\text { No }\end{array}$ \\
\hline $\begin{array}{l}\text { Totals:-- } \\
\text { (366 cases) }\end{array}$ & 9 & 3 & $\begin{array}{c}0 \\
\text { (presumed) }\end{array}$ & 8 & 3 & 4 & 5 \\
\hline
\end{tabular}

authors questioned whether this conversation could have been "built in" to the dreaming pattern and thus affected the dream content. Thus, although these workers "disproved" awareness during anaesthesia, they suggested a factor supporting this possibility in the controls. This author comments that theatre conversation is surely more likely to provide matter of potential interest to a patient than is choir or piano music.

(2) Retrospective studies

Wilson and Turner ${ }^{18}$ investigated 150 obstetrical patients, the majority of whom underwent caesarean sections. There was a 17.3 per cent occurrence of unpleasant recall, associated in 10 cases (6.6 per cent of the total) with recall of pain. Hutchinson ${ }^{21}$ attempted to assess the incidence of awareness in what she termed "an environment of expert modern anaesthesia." From her original 700 patients, this author wishes to consider the 216 who were anaesthetised with a nitrous oxide, oxygen and relaxant technique.

From the case histories given in these two series a table of results has been compiled (Table I). It should be noted that there were more cases of awareness, even with pain, than quoted case histories in the table. Several facts emerge.

Vision disappeared in all nine patients (presumed, but not stated, in two cases). Discomfort persisted in three, pain in four and hearing in eight cases. Thus, the order of disappearance (vision - discomfort - pain - hearing) would suggest that these effects were the result of varying depth of anaesthesia as this is the order of disappearance one would anticipate during progressive anaesthesia. The last two columns in the table show that the experience of pain is always associated with severe psychic upset, and conversely (with one exception) : no pain - no psychic upset. Patients who felt pain must be considered to have been inadequately anaesthetised for the surgical procedure in hand. In two cases, hearing persisted although the patient was anaIgesic.

\section{Awareness during unconsciousness}

There are several types of unconsciousness:

(a) General anaesthesia. 
(b) Pathological unconsciousness (e.g. coma from metabolic disturbance, debilitating disease or cerebral injury).

(c) Sleep - which is different from the other two in that it is a state from which an individual can be roused.

(d) Deep hypnosis (?) which might be considered as an "unconscious state."

In considering the question of awareness during the unconsciousness of general anaesthesia, it would be reassuring if any evidence could be found for some form of awareness during other unconscious states.

Crasilneck and Hall ${ }^{22}$ used hypnosis as part of the general management of ten patients suffering from intractable pain due to terminal cancer. During hypnotic sessions, these patients were conditioned to approximate the thumb and finger of a hand on a given signal under hypnosis. The condition of all these patients gradually deteriorated until each one became clinically unconscious. In spite of this, however, these authors noted that in eight out of these ten patients, approximation of the thumb and finger occurred when this was requested under hypnosis, even though there was no other contact with the patient. Crasilneck and Hall also noted that death occurred within 48 hours in every case which appeared unable to carry out this simple instruction.

Is there any evidence of awareness during sleep? Consider a random stimulus occurring during the night, for example (and many of us have experienced this) the baby's cry will arouse the wife, the doctor (thank goodness) sleeps on; he is alerted by the telephone and his wife sleeps on. These sounds may have a similar noise level but different character and message. Next day both parties can be totally (consciously) unaware of what occurred during the night.

It would seem unnecessary to hypothesize different mechanisms for apparent awareness during different states of unconsciousness. This author suggests that the part of the mind which can remain alert is called "the unconscious mind." It is the part of the mind normally in contact with a therapist during the state of hypnosis.

Awareness during anaesthesia would seem to be always a possibility, but does not necessarily occur. Indeed, conscious recollection of events occurring during surgery is rare. But as it does occur clinically, the question can be asked: If the unconscious mind were to remain alert during anaesthesia - what subject matter would interest it?

Consideration of this could possibly explain the discrepancy between the results of prospective research and clinical experience. It might also give anaesthetists insight into the problem and thus help them to minimise this risk in their clinical practice.

\section{Factors affecting awareness}

(1) The nature of the subject matter

Walter ${ }^{23}$ points out that in the conscious state, attention and comprehension are dependent more on the significance of a stimulus than on its strength. It seems reasonable to assume that the same could apply during "unconscious states"; maybe more so.

Although outwardly calm, virtually all individuals facing surgery will have some degree of apprehension at a "deeper" (unconscious) level. What are the possible fears? 
(a) Fear of not waking up (= fear of death).

(b) Fear of being awake during the operation (=fear of suffering terrible pain and of being unable to indicate this plight - [annotation] $\left.{ }^{24}\right)$. Intubated patients cannot speak.

(c) Fear that "something" (especially cancer) will be discovered at the operation.

(d) Fear of the unborn child (= fear that it will be deformed or stillborn).

Such real fears may dominate the thoughts of the patient throughout the immediate preanaesthetic period and even during the induction of anaesthesia. The unconscious mind will thus become directed to detect any clues that could alleviate these fears; anything said by the surgeon will be of the greatest importance.

(2) Proprioceptive stimuli

Awareness (primarily hearing) during surgery depends upon sensory input, much of which occurs as proprioceptive impulses from the muscles. Inadequate curarization (or the wearing off of this towards the end of an anaesthetic) can be responsible for arousal and the development of a state of potential awareness.

(3) Detail of recall

Cheek ${ }^{8}$ suggests that patients under anaesthesia may absorb perceptual data but that verbatim conversational recall would not occur, nor could this be anticipated. Cheek ${ }^{9}$ also points out that unconscious individuals are terribly vulnerable to pessimistic thoughts. Thus, the individual word might be heard, remembered and incorporated by the patient in an entirely different context.

A theoretical example is given: If during an operation a nurse asked: "Could this develop into cancer?" - only the word "cancer" might be heard by the patient who could then (because of pessimistic thinking) feel that someone had said that he had cancer. A case history described by Cheek and illustrating this will be cited later.

(4) Subconscious memory of events during surgery

Cobb (Editorial ${ }^{5}$ ) pointed out that apart from the occasional patient who consciously remembers discomfort during surgery, it is probable that there are others who only have a subconscious memory of this. Kasasian ${ }^{25}$ expressed this differently, that although the recollection of an event means that information about it is stored in the subconscious mind, this does not imply that the process of storage is contingent upon this memory having been previously registered in the conscious mind.

There is yet another mechanism whereby individuals may have no conscious awareness:

(5) Repression from consciousness of unpleasant memories

Two cases from the literature on awareness will be cited to illustrate this mech. anism.

Winterbottom's $\mathrm{s}^{1}$ letter described what his patient said: "As a matter of fact, doctor, I woke up in the theatre! ... I was awakened by the most excruciating pain in my tummy. It felt as though my whole inside were being pulled out ... I heard the doctors talking ..." Yet subsequently this patient's surgeon wrote that his patient spoke of the memory of her experience "as a matter of interest rather than concern (Wells ${ }^{2 \theta}$ )."

Hutchinson's ${ }^{21}$ series included a frail, old lady who underwent a laparotomy. This patient described her experience: "I awoke in the theatre with a deep pain in my abdomen." She heard an irregular clicking noise "like someone in a hurry," 
and she also heard people talking about football. It was established that a fastworking surgeon was using a ratchet-type needle holder and that, in fact, a forthcoming Cardiff-Springbok rugby match was discussed during the operation! This lady became very distressed when further attempts were made to discover more detail of her experience, yet a week later she denied any unpleasant experience.

The memory of a highly traumatic experience is repressed from the patient's conscious mind because he is unable to face it, but he cannot repress the emotion that went with it. This emotion can have different fates. It can remain free in the patient's unconscious mind - causing so-called free-floating anxiety (the patient is anxious, but doesn't know why); secondary depression can readily develop. This anxiety may become more generalised so as to amount even to a delusional state where the patient entertains ideas of persecution, or it may become so intense that complete withdrawal occurs. The emotion may become "attached" to something else; for example, the patient may develop a phobia which is totally unrelated to the original psychic trauma (i.e. of being awake during surgery).

Awareness may also affect recovery. For example, individual "key words" heard by the patient become misinterpreted and incorporated in an entirely different context; this may delay proper recovery, as is illustrated in a case history cited below. Guilt may also interact in this sequence of events ("I didn't deserve to recover, anyway").

Awareness can thus have far-reaching potential effects on the patient's psyche, which may be aptly described as "the invisible scars of surgery." Although these are rare, no anaesthetist can console hirnself with a negative answer to questions regarding awareness put at the conscious level when suppression has occurred.

\section{Assessment of prospective studies on awareness}

This is a personal evaluation of these carefully-planned attempts to confirm the existence of awareness. It is in no way a condemnation of this work; this author feels that in this field retrospective study will be more rewarding.

Clinical evidence has shown that all details recalled by patients during anaesthesia represented some threat to the individual, either to his safety or to continued good care, even though this may have been incorrectly deduced.

Prospective studies (Levinson's ${ }^{17}$ work excepted) all created an artificial stimulus of no real interest to the patient and irrelevant to the patient's surgical condition or the operation. Moreover, the numbers involved in which a nitrous oxide, oxygen and relaxant technique was used (when the risk for awareness is greatest) were too few in toto for conclusions to be drawn:

Brice et al. -38 cases; McIntyre -17 cases; Terrell et al. -3 or 4 cases, i.e. 58 or 59 cases altogether.

\section{Value of hypnosis in the problem of atvareness}

Hypnosis may be defined as a consent state combining physiological relaxation in which the critical faculty of the conscious mind is by-passed to some degree.

Hypnosis is thus a valuable technique for the investigation of the unconscious mind. From what has been written, it is seen that there can be several reasons why the conscious mind can be "unaware" of events that have been recorded in the unconscious mind. Hypnosis has two uses in the problem of awareness. 
(1) For the complete analysis of prospective studies of awareness at the unconscious as well as the conscious level. Levinson's ${ }^{17}$ contrasting replies at these two levels illustrates the importance of this.

(2) In the hypnoanalysis of patients who present a clinical problem to which questioning at the conscious level fails to give an adequate answer. The many fascinating techniques for the recovery of traumatic material buried in the unconscious mind are beyond the scope of this article. The case described below illustrates hypnoanalysis:

\section{Tachycardia and dyspnoea due to a misunderstanding}

Cheek $k^{9}$ described a 3/2 year old boy who underwent resection of a patent ductus arteriosus. Recovery from surgery was rapid and the child grew up healthy apart from a dramatic tendency to be extremely short of breath when at sport. The boy's pulse rate at such times would exceed 120 beats/min. At the age of ten this boy was investigated by hypnosis using ideomotor responses.

At this age it was possible for this patient to scan his operation concurrently with the ideomotor activity. He recalled one moment near the end of the operation which was disturbing. Cheek writes: "The words were long and he (the boy) could not remember what they were, but the doctor was saying these long words and then said something about "not being able to $6 x$ it." "This boy had the "impression" that his heart was so bad it could not be "fixed." Moreover, prior to his own operation he had witnessed his own grandfather dying from heart failure. Explanation and reassurance has led to a complete recovery and at 18 years old this youth had normal physiological responses to exercise.

\section{Ideomotor finger signalling}

It may be impossible even under hypnosis to recover a highly traumatic experience by questioning that involves verbal replies. Ideomotor responses offer a practical alternative.

Under hypnosis the patient is conditioned to indicate "yes" and "no" by involuntarily lifting a finger in each hand; the patient selects the finger subconsciously. Questions are then put to the patient, phrased so that only a "yes" or "no" answer is required. The technique has been described by Cheek ${ }^{27}$ and Lecron, ${ }^{28}$ and was used by Terrell et $a{ }^{19}{ }^{19}$ in their investigation.

With a true ideomotor response, the finger may tremble and lifts slowly. Voluntary (= conscious) lifting is smoother and more rapid.

\section{Avoidance of awareness}

(1) Detection of too-light anaesthesia

Although the EEc will reveal the presence of deep anaesthesia (Levinson, ${ }^{17}$ Robson $^{29}$ ), the pattern difference between consciousness and the inadequately anaesthetised patient (i.e. whether the perceiving-remembering state is present or absent) are too small to be of practical value (Robson, ${ }^{29} \mathrm{Cobb}^{5}$ ). Indeed, Robson considers that there is as yet no practical means of measuring the depth of anaesthesia within the range demands of modern techniques. The only alternative is our clinical judgment of well-recognised but unsubstantiated clinical signs. 
Graff and Phillips ${ }^{2}$ mention that these can be most subtle, but that we should pay greater heed to them. Robson ${ }^{29}$.describes some of them: eyelid movement, wrinkling of the forehead, slight limb movement, sweating and lachrymation. Also, in the absence of anoxia, pupillary dilatation. For their continual observation there should be good access and proper lighting of the face. Without this, the author advocates the use of inhalational adjuvants.

(2) Avoidance of awareness in the apparently anaesthetised patient

This author considers that the depth of anaesthesia (= degree of unconsciousness) varies continually during an anaesthetic. It follows, therefore, that degrees of partial consciousness ( $=$ risk for awareness) may also occur if the anaesthetic level lightens. This is the particular risk of the technique of relaxant + light anaesthesia; the patient may temporarily "surface" into a zone of partial or complete awareness. Graff and Phillip's ${ }^{2}$ experience bears this out; their patient "had been intermittently conscious and unconscious during the three-hour anaesthetic period."

The many technical factors which can risk this state of affairs have been well discussed by Waters ${ }^{30}$ who gives adequate technique detail to minimise this risk. In addition, this author considers that conversation during surgery should always be discreet, both in topic and sound level. This is especially important during the early stages of an operation, during intermittent depolarizing-relaxant techniques, and during caesarean sections. Discussion of any subject which could "interest" the patient (e.g. prognosis, cancer, etc.) should be carried out at a voice level so that even nurses present might have difficulty in hearing exactly what was being said. Cheek" writes: "Careless remarks can obliterate hope and destroy the effects of constructive therapy and surgery."

General frivolity and story telling with raucous laughter should be taboo. It is indeed sad that this still sometimes occurs.

The addition of inhalational adjuvants, even intermittently, will ensure that the patient is kept asleep during relaxant techniques. They have been repeatedly recommended (e.g. editorial, ${ }^{3}$ Stephen, ${ }^{15}$ Lee and Atkinson, ${ }^{31}$ p. 154). Harris, Brice, Hetherington and Utting ${ }^{32}$ found that the addition of $0.5-0.3$ per cent halothane completely eliminated dreaming, which patients have found unpleasant. As halothane is unsuitable for routine use in operative obstetrics, Crawford ${ }^{\text {sa }}$ investigated the effect of 0.1 per cent methoxyflurane, and noted only one instance of awareness in 424 obstetric cases. It must be remembered that inhalational adjuvants have a variable potentiating effect on muscle relaxants.

Earplugs are used openly by some anaesthetists. Cotton wool is adequate but more effective plugging wool is available in industry. Earplugs can be considered when there is a previous history of awareness, when continual student explanations have to be made, and when adequate premedication is contraindicated (e.g. caesarean sections, poor risk, anaemic and cardiac cases and some emergencies). Adequate anaesthesia must always be maintained, otherwise pain may be felt.

As anaesthetists, we have a moral obligation, not only to relieve pain and apprehension of our patients, but also to assure their oblivion as well as safety during surgery.

'Billesholms Anti-noise ear wool. Ardent Industral Service, 100 Wigmore Street, London, W.1. 


\section{ACKNOWLEDGMENT\$}

I am most indebted to MEDLARs (Medical Literature Analysis and Retrieval System) for an initial gratis computer search of the literature on this subject. Address: U.K. MEplars Service, National Lending Library, Boston Spa, Yorkshire, LS23 7 BQ., Great Britain. Also to Dr G.J.F. Briggs for helpful criticism of the manuscript.

I also wish to thank, without permission, those anaesthetists who took the trouble to write up their cases of awareness, without which this article would have been impossible.

\section{SUMMaky}

The author presents his personal evaluation of the nature of awareness during anaesthesia. This is primarily based on the actual cases described in the literature to date.

When a patient feels pain or discomfort (and also hears), this must be clearly interpreted as inadequate anaesthesia. In the absence of pain or discomfort and when the patient is apparently "properly anaesthetised," awareness has consistently been characterized by the persistence of hearing.

The level of anaesthesia fluctuates during an anaesthetic. The patient may thus enter a "zone of subconscious attention" when there is a risk that he may hear something. This risk will be greater if the patient is worried about his condition (increased subconscious activity). Conversation during the operation should always be discreet, both in topic and sound level. Earplugs are of value, especially when the operation demands very light anaesthesia, or higher oxygen percentage (e.g. Caesarean sections and poor risk cases).

Hypnosis is of value in research on awareness and possibly in the treatment by hypnoanalysis of a patient who has been adversely affected by the subconscious memory of events during surgery.

Subconscious traumata should be regarded as "the invisible scars of surgery." They may have a profound effect on the patient's psyche and future life. It is the anaesthetist's duty always to ensure oblivion as well as analgesia during surgery.

\section{RÉSUMÉ}

L'âuteur présente sa façon personnelle d'évaluer l'état de conscience du malade durant l'opération. Au départ, cela est basé sur les cas trouvés dans la littérature actuelle.

Lorsquiun malade ressent de la douleur ou manque de confort (et aussi peut entendre) il faut conclure que, de toute évidence, l'anesthésie est inadéquate. En l'absence de douleur ou de manque de confort, si le malade semble anesthésié adéquatement, l'état de conscience a toujours été caractérisé par le persistance de Youie.

Les niveaux d'anesthésie peuvent varier au cours d'une opération. Le malade peut, en conséquence, atteindre une "zone d'attention subconsciente" et c'est à ce 
moment qu'il peut entendre ce qui se dit. Cette possibilité d'entendre sera plus grande si le malade est inquiet de son état personnel (activité subconsciente accrue). Les conversations au cours des opérations devraient toujours être discrètes aussi bien sur le sujet de la conversation que sur la force de la voix. Des bouchons dans les oreilles peuvent toujours être d'une certaine utilité, particulièrement si l'opération ne requiert qu'une anesthésie superficielle ou un pourcentage d'oxygène plus élevé (au cours d'une césarienne ou chez les mauvais risques).

L'hypnose peut avoir de la valeur dans la recherche de létat de conscience et également, dans le traitement, par hypnoanalyse, d'un malade qui aurait été psychiquement touché par le souvenir subconscient d'évènements survenus au cours de la chirurgie.

Les traumatismes subconscients pourraient être envisagés comme des cicatrices invisibles de la chirurgie sur le psychisme du malade et, sur son avenir, ils peuvent exercer des influences importantes. C'est à l'anesthésiste qu'il appartient de fournir, au cours de la chinurgie, l'inconscience aussi bien que l'analgésie.

\section{REFERENCES}

1. Winterbottom, E.H. Insufficient anaesthesia (correspondence). Brit. Med. J., 1: 247 (1950).

2. GrafF, T.D. \& Phillips, O.C. Consciousness and pain during apparent surgical anaesthesia. JAMA, 170: 2069 (1959).

3. Editorial. Brit. Med. I., 2: 810 ( 1959 ).

4. Editorial. Lancet, 2: 1394 (1961).

5. Editorial. Anesthesiology, 22; 314 ( I961).

6. Alment, E.A.J. Consciousness during strgical operation (correspondence). Brit. Med. J, 2: 1258 (1959).

7. BaHL, C.P. \& WADwA, S. Consciousness during apparent surgical anaesthesia. Brit. J. Anaesth., 40, 289 (1968).

8. Chesk, D.B. Further evidence of persistence of hearing under chemo-anesthesia: detailed case teport. Amer. J. Clin. Hypnosis, $7: 55$ (1964).

9. CHEEK, D.B. The meaning of continued hearing sense under general chemo-anesthesia: a progress report and report of a case. Amer. J. Clin. Hypnosis, 8: 275 (1966).

10. ChawFone, J.S.; HARLEY, N.F; BLAND, E.F.; \& Shaf, J.L. Awateness during anaesthesia (correspondence). Brit. Med. J., I: 508 (1969).

I1. MarX, G.F.; Steen, S.N.; Schapira, M.; Foster, E.S.; Arkins, R.E.; JofFe, S.; \& KePes, E. Pain and awareness derring surgical anesthesia. New York J. Med, 67: 2623 (1967).

12. Rosev, J. Hearing tests during anaesthesia with nitrous oxide and relaxants. Acta anaesth. Scandinav, $3: 1$ (1959).

13. SIA, R.L. Consciousness during general anesthesia. Anesth. \& Analg., 48: 363 (1969),

14. Smiтu, A.M. McNeIL, W.T, Awareness during anaesthesia (correspondence). Brit. Med. J., 1:572 (1969).

15. Srepyen, C.R. Awareness during anesthesia. Clin. Anesthesia, 3: 114 ( 1968 ).

16. WuLson, J. \& Tuner, D.J. Awareness during Caesarean section under general anaesthesia. Brit. Med. J, 1: 280 (1969).

17. Levinson, B.W. States of awareness during general anaesthesia. Brit. J. Anaesth., 37: 544 (1965).

18. MCINTYhe, J.W.R. Awareness during general anaesthesia: preliminary observations. Canad. Anaesth. Soc. I., 13:495 (1966).

19. Terrell, R.K.; SweEt, W.O.; GLadfelter, J.H.; \& StepheN, C.R. Study of recall duting anesthesia. Anesth. \& Analg., 48:86 (1969).

20. Brice, D.D.; Hethenincton, R.R.; \& UtTiNC, J.E. A simple study of awareness and dreaming during anaesthesia. Brit. J. Anaesth, 42: 535 (1970),

21. Hutchinson, $R$, Awareness during surgery. A study of its incidence. Brit. I. Anaesth., 33: $463(1960)$.

22. Chasilneck, H.B. \& Hall, J.A. The use of hypnosis with unconscious patients. Internat. J. Clin. Exper. Hypnosis, 10: 141 (1962). 
23. WA1,TER, W,G, Author: Ch. II, Modern Trends in Anaesthesia. Edited by Evans, F.T, and Gray, T.C. London; Butterworth (1958). p. 42.

24. Annotation. Lancet, $1: 1188$ ( 1968 ).

25. Kassian, A.H. Awareness during anaesthesia (correspondence). Brit. Med. J., 1: 507 (1969).

26. WELLS, C. Insufficient anaesthesia (correspondence). Brit. Med. J, I: 610 (1950).

27. CHEEK, D.B. Removal of subconscious resistance to hypnosis using ideomotor questioning techniques. Amer. J. Clin. Hypnosis, 3: 103 (1960).

28. LECRON, L.M. The uncovering of early memories by ideomotor responses to questioning. Internat. J. Clin. Exper. Hypnosis, I1: 137 ( 1963)

29. Ronson, J.C. Measurement of depth of anaesthesia. Brit. J. Anaesth., 41: 785 (1969).

30. Waters, D.J. Factors causing awareness during surgery. Brit. J. Anaesth., 40: 259 (1968).

31. LEE, J.A. \& ATKInson, R.S. A Synopsis of Anaesthesia 6th ed, Bristol: John Wright (1968). p. 154.

32. Hafris, T.J.B.; Brice, D.D.; Hetherington, R.R.; \& Utting, J.E. Dreaming associated with anaesthesia: The influence of morphine premedication and two volatile adjuvants. Brit. J. Anaesth., 43: 172 (1971).

33. Crawrokp, J.S. Awareness during operative obstetrics under general anaesthesia. Brit. J Anaesth., 43: 179 ( I971). 